\title{
A strikingly coloured new giant millipede from Vietnam has copycat in Borneo (Diplopoda, Spirostreptida, Harpagophoridae)
}

\author{
Piyatida PIMVICHAI ${ }^{1, *}$, Nesrine AKKARI ${ }^{2}$, Irina SEMENYUK $^{3}$, \\ Jerôme CONSTANT ${ }^{4} \&$ Henrik ENGHOFF ${ }^{5}$ \\ ${ }^{1}$ Department of Biology, Faculty of Science, Mahasarakham University, \\ Mahasarakham 44150, Thailand. \\ ${ }^{2}$ Naturhistorisches Museum Wien, Burgring 7, 1010 Vienna, Austria. \\ ${ }^{3}$ A.N. Severtsov Institute for Problems of Ecology and Evolution, Russian Academy of Sciences, \\ Leninsky pr. 33, Moscow 119071, Russia. \\ ${ }^{3}$ Joint Russian-Vietnamese Tropical Center, Street 3 Thang 2, 3, Q10, Ho Chi Minh City, Vietnam. \\ ${ }^{4}$ Royal Belgian Institute of Natural Sciences, O.D. Taxonomy \& Phylogeny - Entomology, \\ Vautier street 29, B-1000 Brussels, Belgium. \\ ${ }^{5}$ Natural History Museum of Denmark, University of Copenhagen, Universitetsparken 15, \\ DK-2100 Copenhagen Ø, Denmark. \\ *Corresponding author: piyatida.p@msu.ac.th \\ 2Email: nesrine.akkari@nhm-wien.ac.at \\ 32Email: free-cat@bk.ru \\ ${ }^{4}$ Email: jconstant@naturalsciences.be \\ ${ }^{5}$ Email: henghoff@snm.ku.dk

\footnotetext{
${ }^{1}$ urn:Isid:zoobank.org:author:4D882A89-E0C1-4F78-93E7-FA1B5A2650F2

${ }^{2}$ urn:1sid:zoobank.org:author:DC6FB247-5F4F-4700-9DB6-6588A99370A0

${ }^{3}$ urn:1sid:zoobank.org:author:5926D032-BDC8-42D1-B3FF-087CDC6AA5D7

${ }^{4}$ urn:lsid:zoobank.org:author:6E6072A1-9415-4C8D-8E60-2504444DB290

${ }^{5}$ urn:lsid:zoobank.org:author:FB09A817-000D-43C3-BCC4-2BC1E5373635
}

\begin{abstract}
A new giant species of the subfamily Rhynchoproctinae with strikingly bi-coloured, redyellow legs contrasting with a black body is described: Alienostreptus bicoloripes sp. nov. from Vietnam. The new species is assigned to the genus Alienostreptus Pimvichai, Enghoff \& Panha, 2010 hitherto comprising one species, A. alienus (Attems, 1936), and differing from other rhynchoproctine genera by having the femoral spine duplicated. Species of this genus share three synapomorphic characters of the subfamily, viz (1) anterior coxal fold forms deep concavity in posterior view, (2) posterior coxal fold very low, and (3) posterior coxal fold with mesal flap. A superficially very similar colourful species from Borneo, also with bi-coloured legs but clearly not belonging to Alienostreptus due to the position of ventral soft pads on male legs, is documented based on photographs.
\end{abstract}

Keywords. New species, Southeast Asia, taxonomy. 
Pimvichai P., Akkari N., Semenyuk I., Constant J. \& Enghoff H. 2020. A strikingly coloured new giant millipede from Vietnam has copycat in Borneo (Diplopoda, Spirostreptida, Harpagophoridae). European Journal of Taxonomy 722: 1-15. https://doi.org/10.5852/ejt.2020.722.1129

\section{Introduction}

Most of the large to gigantic millipede species in Southeast Asia belong to the family Harpagophoridae Attems, 1909. Based mainly on gonopodal characters, Jeekel (2006) divided the family into three subfamilies, viz, Harpagophorinae Attems, 1909, Adiaphorostreptinae Hoffman, 1977 and Rhynchoproctinae Demange, 1961. The subfamily Rhynchoproctinae is a monophyletic group sharing three synapomorphic gonopodal characters: anterior coxal fold $(a c)$ forming a deep concavity in posterior view; posterior coxal fold $(p c)$ very low; posterior coxal fold mesally with a 'flap-like' process (Pimvichai et al. 2010). The subfamily currently includes 35 species in 14 genera (Zhang et al. 1997; Jeekel 2006; Pimvichai et al. 2010). The genus Alienostreptus Pimvichai, Enghoff \& Panha, 2010 differs from other rhynchoproctine genera by having duplicated femoral spines.

The majority of species of the subfamily Rhynchoproctinae is distributed in southern China, Myanmar, Thailand, Laos, Cambodia and Vietnam. A few species are distributed in Borneo, Malacca Peninsula, Sumatra, Sunda Islands and as far south as Lombok.

Until now, only two species in two genera of Rhynchoproctinae have been reported from Vietnam, viz, Alienostreptus alienus (Attems, 1936) and Uriunceustreptus uniserialis (Attems, 1938). Based on new material from Vietnam, we describe a new colourful giant millipede, the second species of the genus Alienostreptus. The present study provides a new diagnosis of the genus in order to include the new species.

Several photographs of a superficially very similar species from Borneo exist, but no specimen has been available. The Bornean species is strikingly similar to the new species from Vietnam. However, the colour of the legs is slightly different, and the position of the ventral soft pads on male legs is also different. We, therefore, regard the Bornean specimens as belonging to a genus different from Alienostreptus.

\section{Material and Methods}

Specimens were examined from the following collections:

NHMW $=$ Naturhistorisches Museum Wien, Vienna, Austria

RBINS = Royal Belgian Institute of Natural Sciences, Brussels, Belgium

ZMUM = Zoological Museum, State University of Moscow, Russia

The morphological terminology follows previously published papers (Pimvichai et al. 2009, 2010). Living specimens were photographed with a digital camera.

Measurements and photographs were made with a Nikon DS-Fi2 camera mounted on a Nikon SMZ25 stereo microscope, using the NIS-Elements Microscope Imaging Software with an Extended Depth of Focus (EDF) and edited in Adobe Photoshop CS6.

Gonopods drawings were performed with pencil and then black liners using a Olympus SZ-61 stereo microscope, sketches were scanned with a CanoScan Lide 60 scanner and then edited with Corel PhotoPaint X5 software. Figure plates were assembled in Adobe Photoshop CS6. 


\section{Gonopod terminology}

We use the following terminology for the gonopod structure of the genus Alienostreptus (terms not in Pimvichai et al. 2010 in bold):

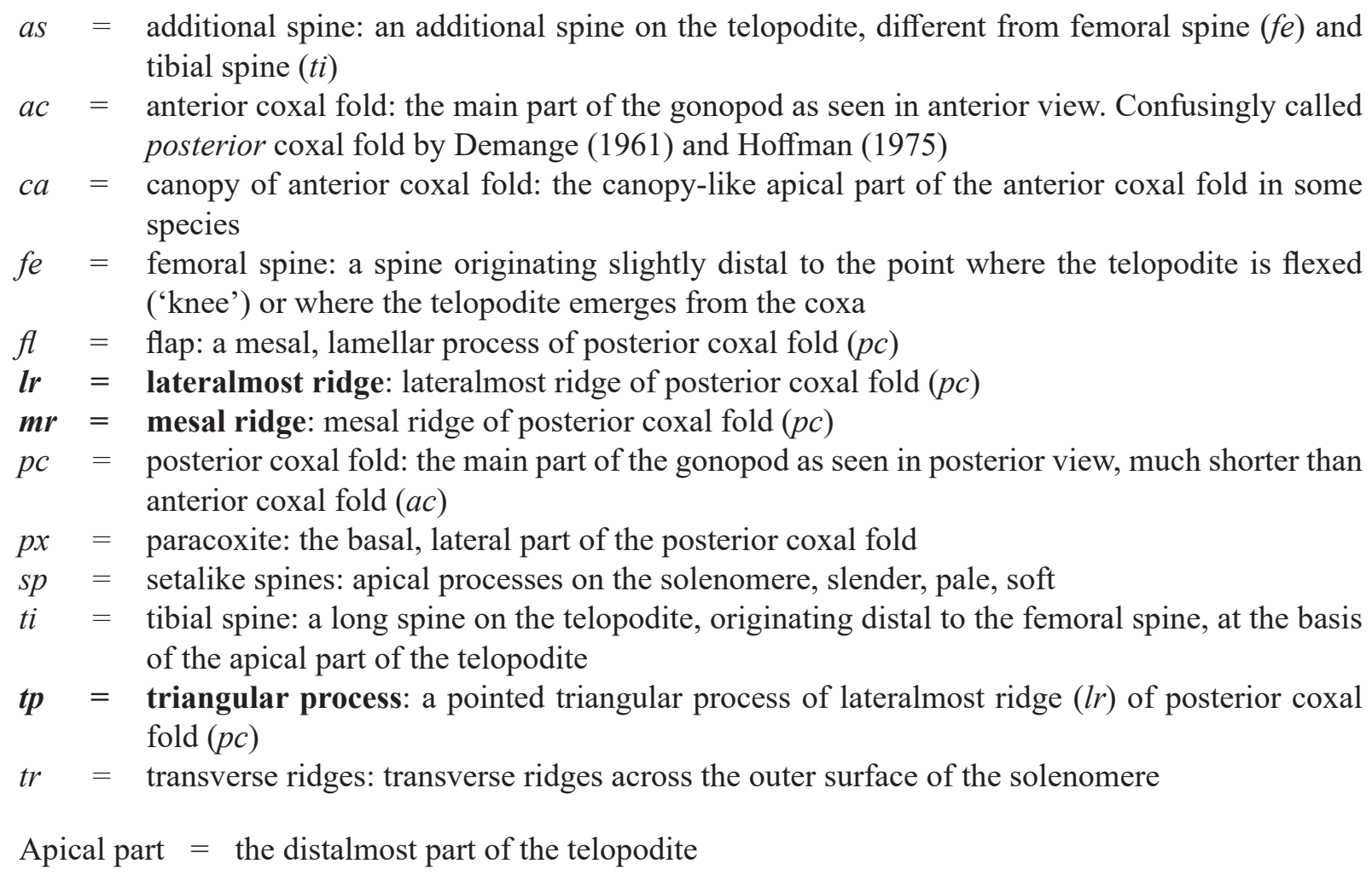

\section{Results}

\section{Taxonomy}

Class Diplopoda Blainville-Gervais, 1844

Order Spirostreptida Brandt, 1833

Family Harpagophoridae Attems, 1909

Subfamily Rhynchoproctinae Demange, 1961

Genus Alienostreptus Pimvichai, Enghoff \& Panha, 2010

Alienostreptus Pimvichai et al., 2010: 58.

\section{Type species}

Thyropygus alienus Attems, 1936, by original designation. This until now monotypic genus was erected by Pimvichai et al. (2010) who agreed with Jeekel (2006) that Thyropygus alienus is not congeneric with Thyropygus mundus Attems, 1936, type species of Cercostreptus Demange, 1961, a genus originally, but invalidly, created as a new subgenus of Anurostreptus Attems, 1914 by Attems (1942).

In the morphology-based phylogeny of Rhynchoproctinae by Pimvichai et al. (2010), Alienostreptus comes out in the middle of a paraphyletic sequence of one-genus branches, between Balustreptus Hoffman, 1980, and Winklerostreptus Demange, 1969. Phenetically, Alienostreptus is most similar to Balustreptus, sharing a series of transverse ridges across the apical part of the telopodite, presence of more than one spine on gonopod telopodites, presence of tarsal pads covering the entire ventral surface 
only on tibia of walking legs, and an unmodified collum. From Balustreptus, Alienostreptus differs, i.e., by having two 'femoral' spines on the gonopods as well as having the apical part of the telopodite broadly expanded.

Pimvichai et al. (2010) diagnosed the genus Alienostroptus based on one species, viz, Alienostreptus alienus (Attems, 1936). Here, we revise the genus diagnosis to accommodate the new species (characters changed from Pimvichai et al. 2010 in bold):

A genus of Rhynchoproctinae. Collum narrowed laterally, ends rounded-truncate, with strong anterolateral marginal groove and ridge; stipes of mandibles with a ventral abruptly narrowed swollen lobe; coxae of the seventh pair of legs unmodified; ventral soft pads only on tibiae on all legs except first two pairs; epiproct with a projection; hypoproct completely fused with epiproct. Gonopod sternum (st) absent; flap ( $f$ ) tongue-shaped, thin, projecting caudad from mesal margin of coxa; femoral spine long, duplicated $(f e)$; apical part of telopodite broadly expanded, with several strong transverse ridges $(t r)$ across outer surface, apically with a row of pale spines $(s p)$.

\section{Alienostreptus alienus (Attems, 1936)}

Figs 1,8

Thyropygus alienus Attems, 1936: 260.

Anurostreptus (Cercostreptus) alienus - Attems 1938: 95.

"Cercostreptus" alienus - Jeekel 2006: 41.

Alienostreptus alienus - Pimvichai et al. 2010: 59, fig. 5.

\section{Diagnosis}

Differs from A. bicoloripes sp. nov., the only known congener, as specified below in the diagnosis of the new species.

\section{Material studied}

VIETNAM • 1 万, syntype of Thyropygus alienus Attems, 1936, dissected, broken into three parts, extra vial with gonopods, of which one dissected and missing telopodite (NHMW 2556), one leg and one telopodite (NHMW 2604); "Dran Langbian Prov., S. Annam Calcutta M. 1934, leg. C. Boden Kloss, iii-v.1918.”; NHMW 2556, NHMW 2604.

\section{Notes}

See Attems (1936) and Pimvichai et al. (2010) for the full description of this species. The gonopods of $A$. alienus were fully illustrated (Pimvichai et al. 2010: fig. 5). Here, we document the syntype of A. alienus housed in NHMW, also for comparison with the new species (Fig. 1).

Alienostreptus alienus is known from the type locality in Vietnam, South Annam, D'Ran, 3000 feet, Lam Dong Province, and from Vietnam Lam Dong Province, Klong Klanh ranger station, Bidoup-Nui Ba National Park (Pimvichai et al. 2010; Fig. 8). (Locality names updated to presently valid forms.) 


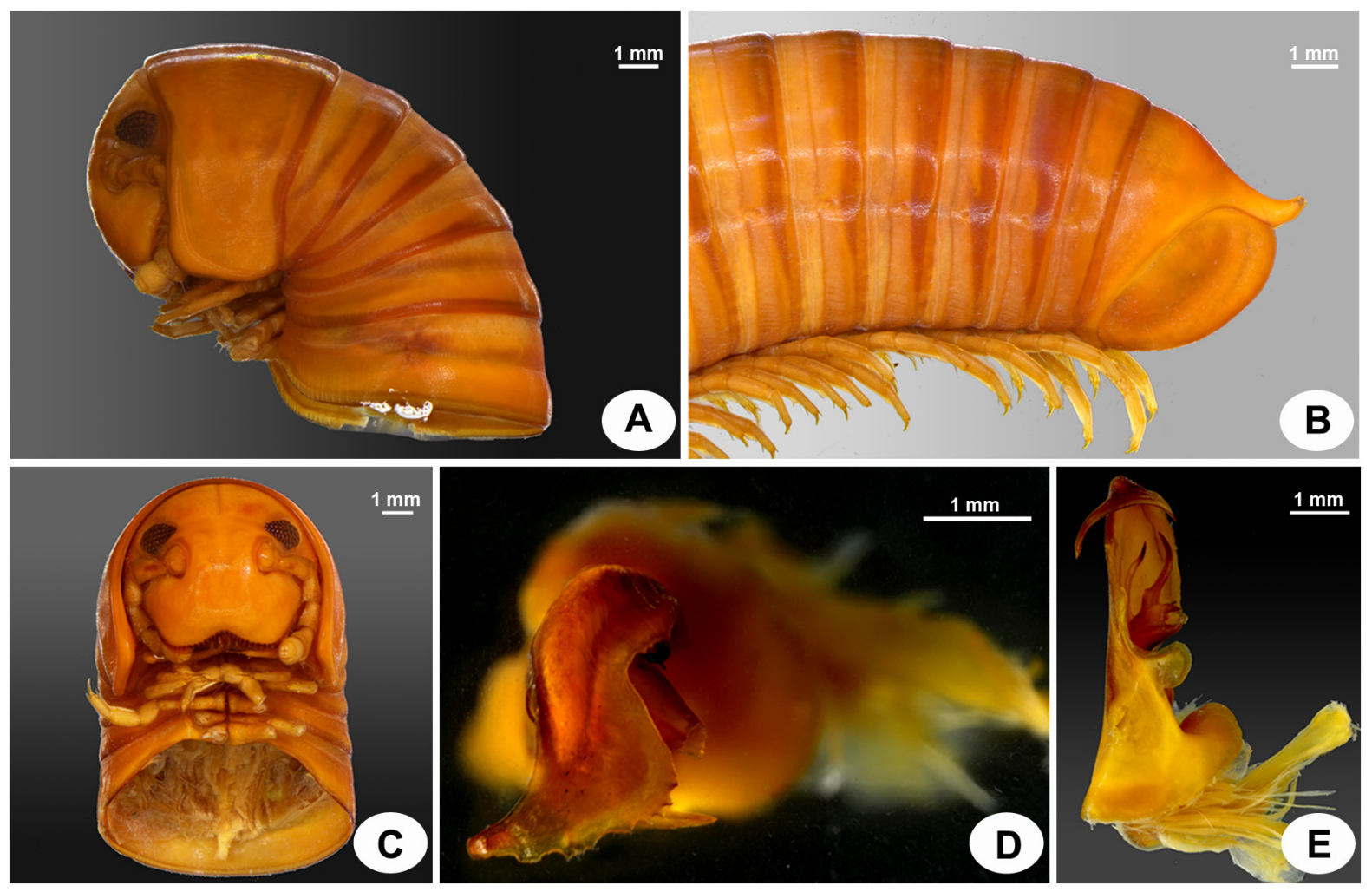

Fig. 1. Alienostreptus alienus (Attems, 1936), syntype (NHMW 2556). A. Head and anterior body rings, lateral view. B. Ultimate body rings, lateral view. C. Head and first body rings, ventral view. D. Right gonopod coxa, apical view. E. Right gonopod (distal part of telopodite broken), posterior view.

Alienostreptus bicoloripes sp. nov. urn:lsid:zoobank.org:act:2142CC0F-B6FD-40C6-8A7C-B3F291D5882E

Figs. 2-6, 8

\section{Diagnosis}

Differs from the only other species in the genus, A. alienus, by:

- larger size

- $\quad$ straight preanal process (epiproct)

- tip of anterior coxal fold (ac) forming a flattened, sickle-shaped lamella with serrate margins

- canopy of anterior coxal fold $(c a)$ with a broad, rounded lobe (in A. alienus with serrate margins)

- apical part of telopodite forming a single broadly expanded sheet, in A. alienus ending in two branches

- tibial spine much shorter than in A. alienus

\section{Etymology}

The species epithet refers to the strikingly bi-coloured legs.

\section{Type material}

\section{Holotype}

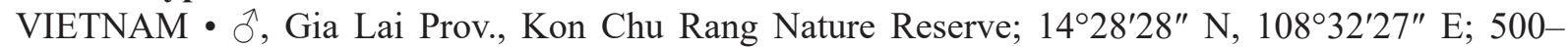
1200 m a.s.1.; 13-20 Jul. 2018; J. Constant, J. Bresseel and X. Vermeersch leg.; GTI project; RBINS I.G.33.769/001. 


\section{Paratypes}

VIETNAM • 1 §, 2 우; same collection data as for holotype; RBINS I.G.33.769/002, I.G.33.769/003,

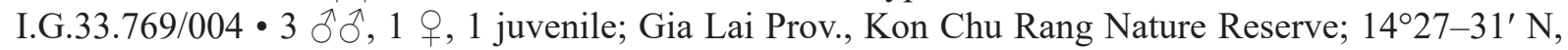
108³2-36' E.; 950-1050 m a.s.1.; 23 May-2 Jun. 2016 and 26 Mar.-6 Apr. 2018; I. Semenyuk leg.; ZMUM.

\section{Description}

\section{Males}

Adult males (the holotype and paratypes) with 58-60 podous rings, no apodous rings. Length $16-17 \mathrm{~cm}$, width 10.3-10.5 mm. Overall colour of living specimen (Fig. 2A-C) including antennae, prozona, metazona, epiproct, paraprocts and hypoproct dark brown (almost black). Legs and antennae bi-coloured, antennomeres $1-4$, legs from coxae to postfemora brownish orange; antennomeres 5-7, tibiae and tarsi of legs yellow.

HeAD. Head capsule smooth, no supralabral setae; eyes moderate in size, ommatidia in 7 horizontal rows, eye of one male with $9+10+9+8+6+5+3=50$ ommatidia.

ANTENNAE. Almost reaching back to body ring 3, length of antennomeres: $2>3>4>5>1>6>7$.

MANDIBLE. Stipes with disto-posterior lobe, ventral side of lobe thickened, with pale, soft area.
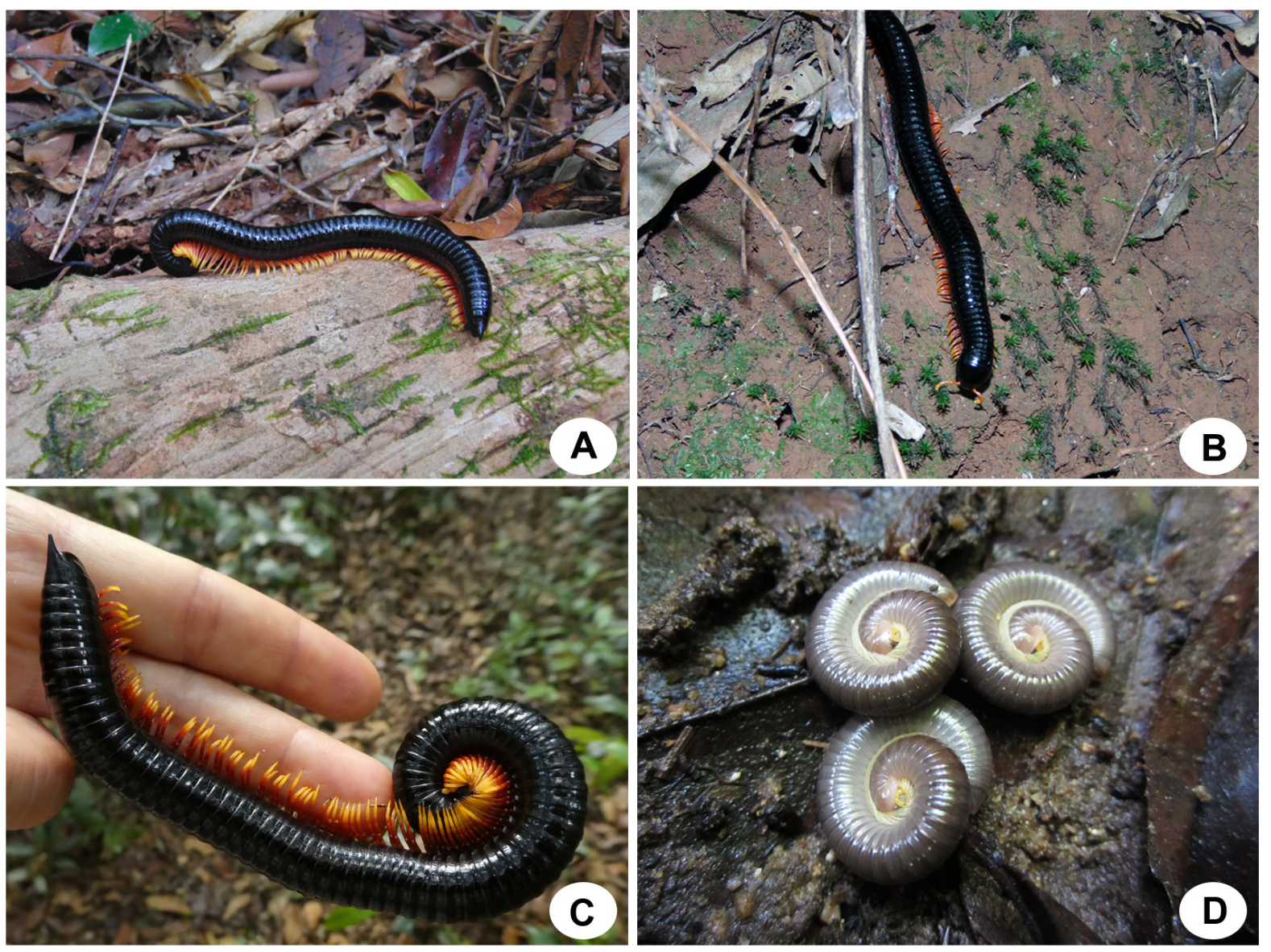

Fig. 2. Alienostreptus bicoloripes sp. nov. A-C. Living females (from Kon Chu Rang Nature Reserve, Gia Lai Province), paratypes (RBINS, ZMUM). D. Living juveniles from Kon Plong protected forest, Kon Tum Province. 
Gnathochilarium. Stipites distally with ovoid, poorly sclerotized, hairless area in middle of which small sclerotized 'island' carries one single spine-like seta.

Collum (Fig. 3A). Lateral lobe anteriorly with large, smooth, rounded, protruding extension; posteriorly with rectangular corner and several wrinkles.

BoDY RINGS. With slightly vaulted metazona and with distinct longitudinal striation on metazona, more distinct on ventral parts but extending to dorsal parts as well; ozopores small, situated up to $2 \times$ their diameter behind suture. No sigilla.

EPIPROCT (Fig. 3B). With long, straight process protruding beyond paraprocts. Paraprocts smooth, with rounded margins ('lips').

STERNA. Smooth, stigmatal grooves short and shallow, reaching to tip of coxae.

LEGS. Relatively long; tarsi, tibiae and part of postfemora visible from above when legs are extended laterad. Length of podomeres: femur $\approx$ tarsus $>$ tibia $>$ prefemur $>$ postfemur $>$ coxa $>$ claw. Claw slender, length almost $4 \times$ proximal height, no accessory claw. Prefemora dorsally with blunt longitudinal ridge. Coxae of seventh pair of legs not modified. Setation of posterior leg from a midbody ring: coxa: 5 ventral setae; prefemur: 3 dorsal spinelike setae, one long and several short, ventral fine setae; femur: 4 ventral fine setae; postfemur: 3 ventral fine setae; tibia: no setae; tarsus: 1 apicodorsal and 4 ventral
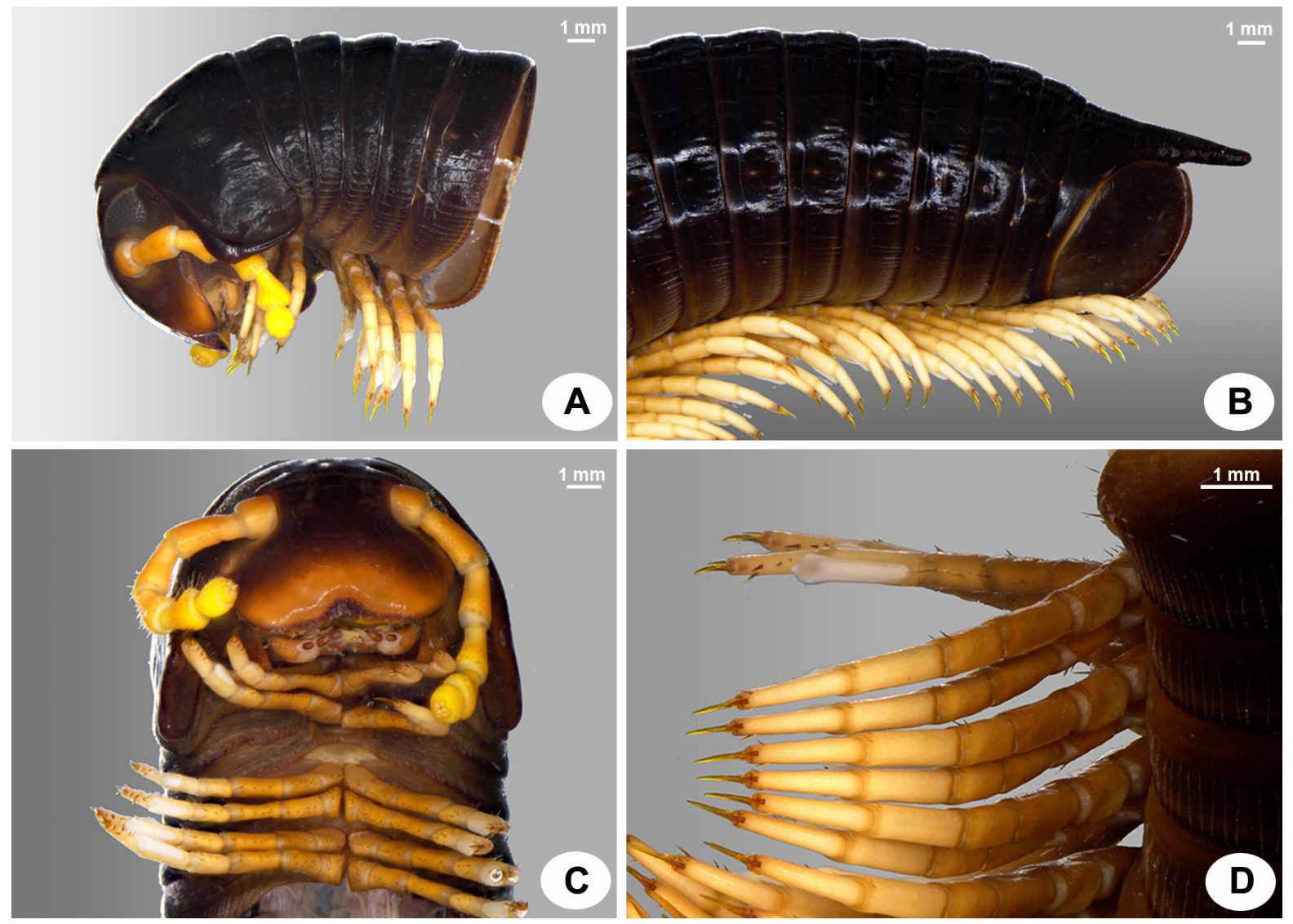

Fig. 3. Alienostreptus bicoloripes sp. nov., holotype (RBINS I.G.33.769/001). A. Head and anterior body rings, lateral view. B. Ultimate body rings, lateral view. C. Head and anterior body rings including seventh pair of legs, ventral view. D. Legs showing soft ventral pads, lateral view. 
spinelike setae. Ventral pads (Fig. 3C-D) only on tibiae, on all legs except first two pairs, pad relatively long, distal ends overlapping ca $1 / 3$ of tarsi, terminating in triangular projection.

Gonopods (Figs 4-5). Sternum absent. Paracoxites $(p x)$ forming small triangular lobe laterally at base of coxae. Coxae oval, apically rounded. Anterior coxal folds (ac) (Figs 4A, 5A) oval (narrower than in A. alienus), forming $\mathrm{V}$-shaped longitudinal trough in anterior view, each $a c$ concave in posterior view;

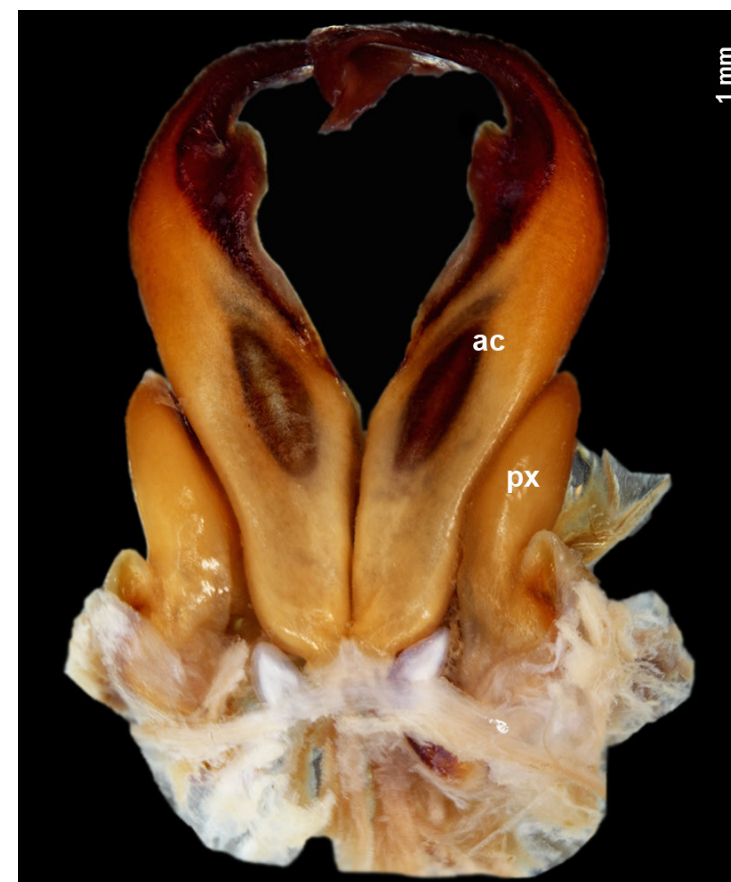

A

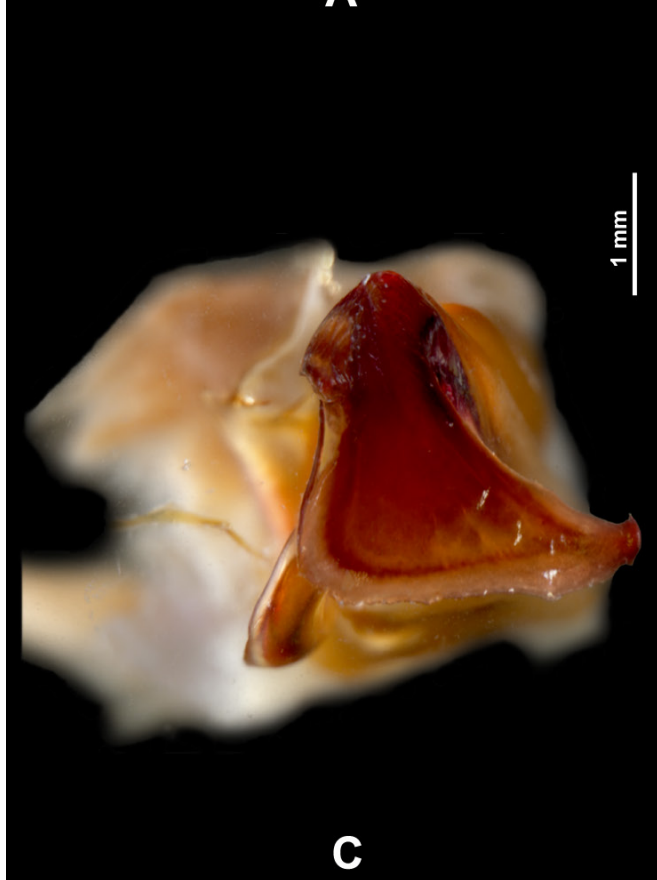

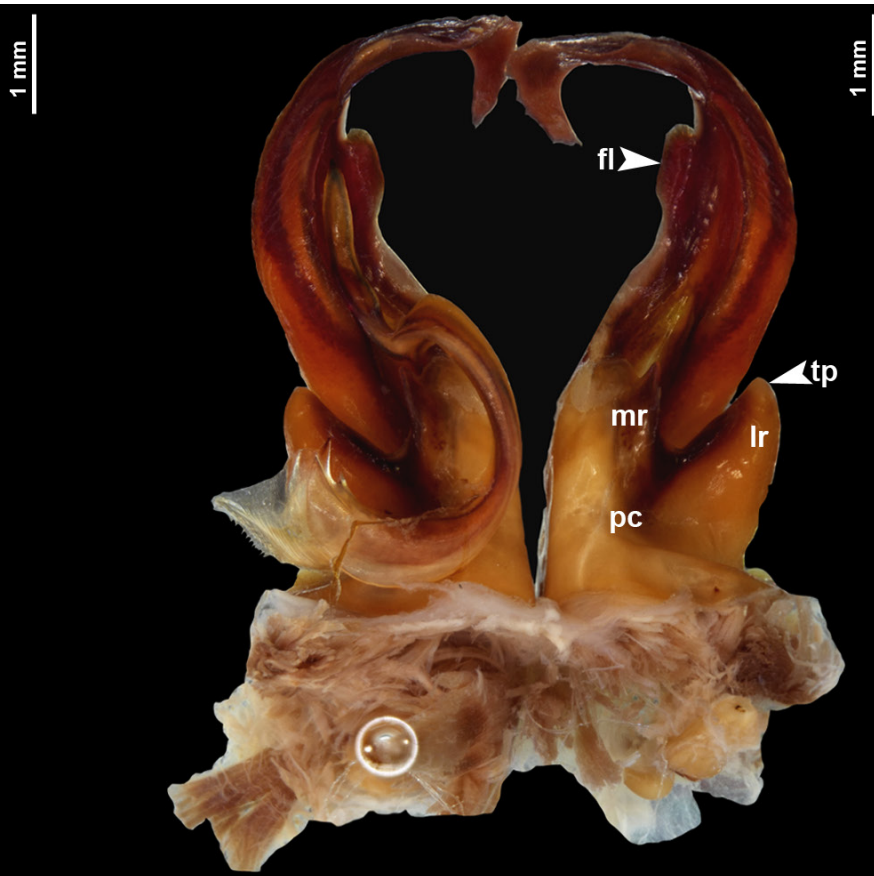

B
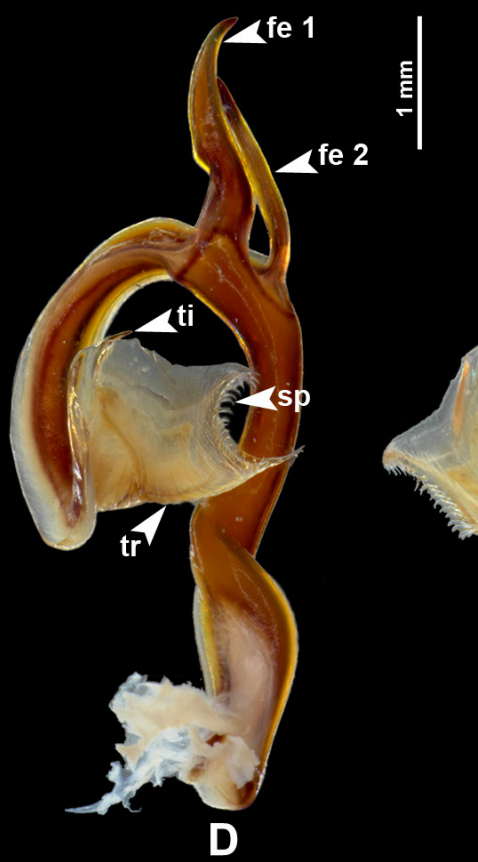


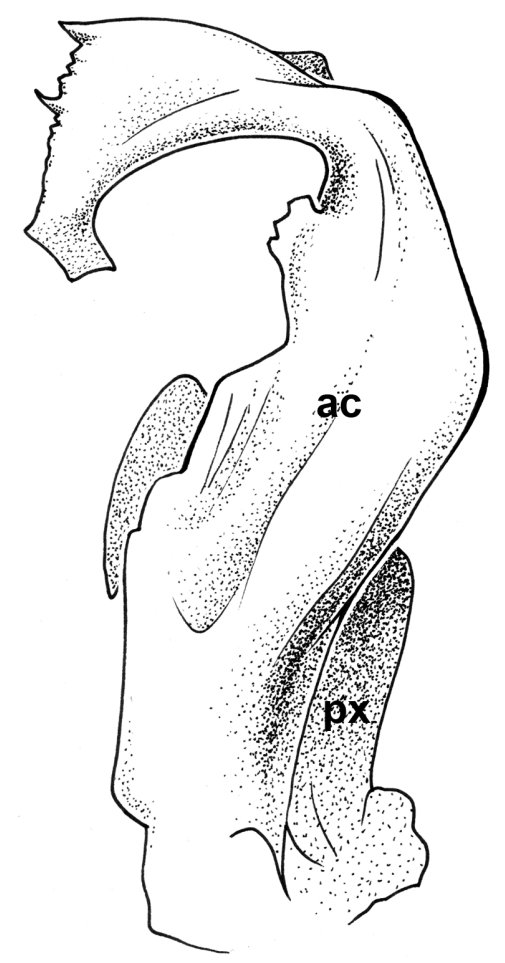

A

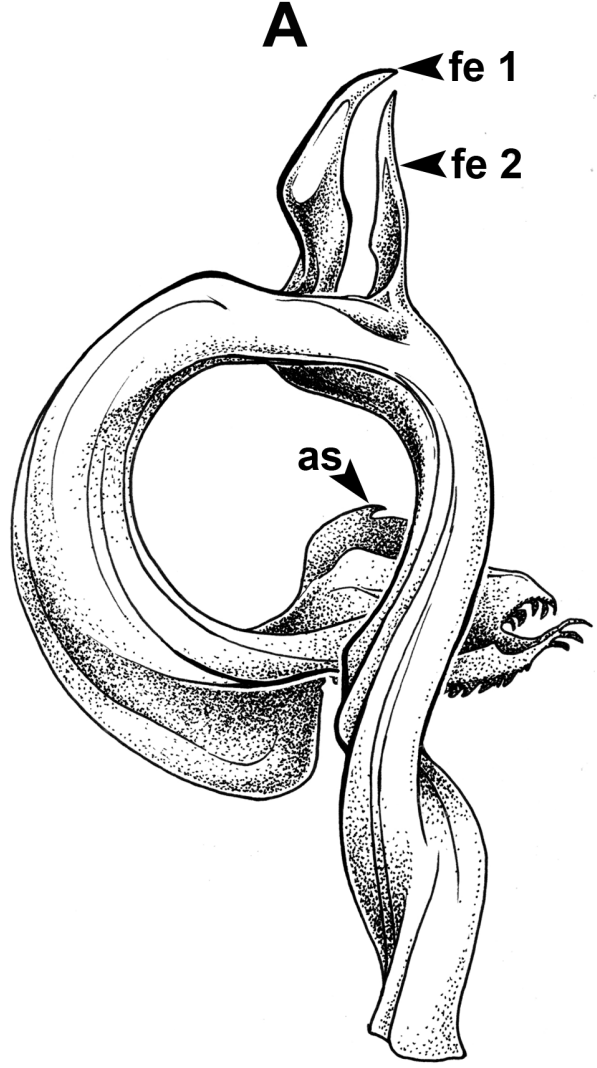

C

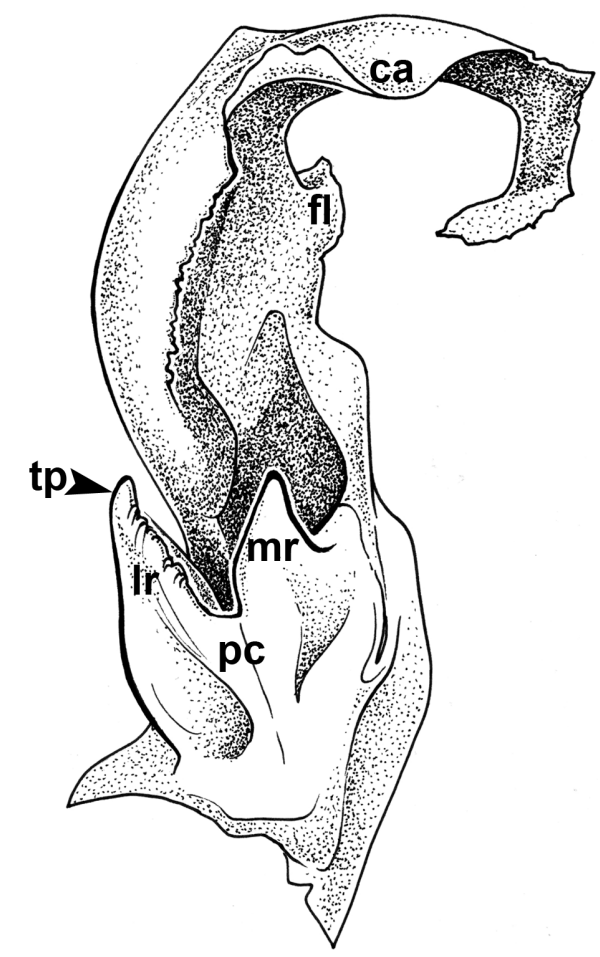

B

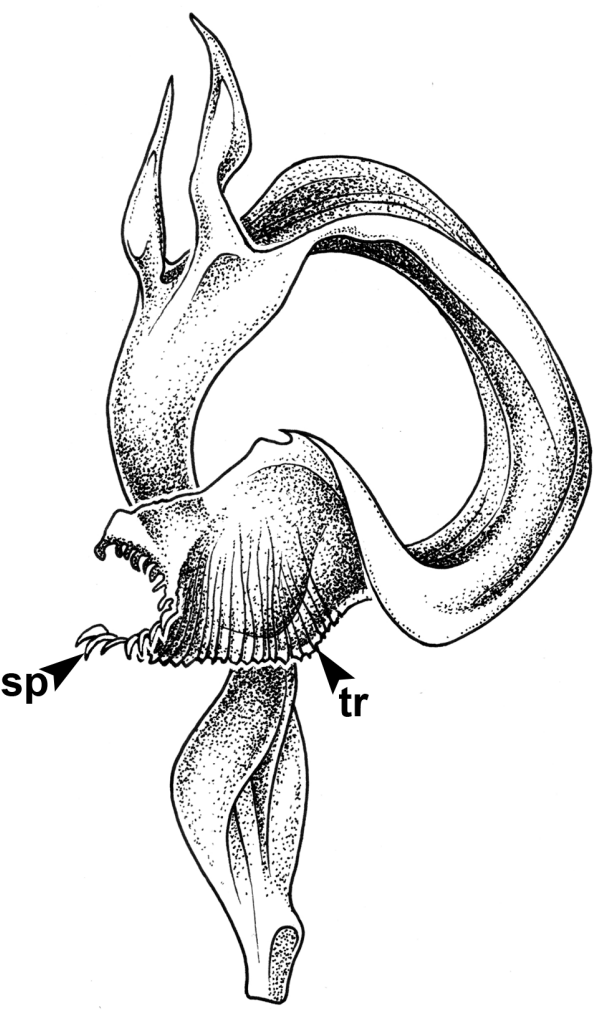

D

Fig. 5. Alienostreptus bicoloripes sp. nov., paratype (ZMUM). A. Right anterior gonopod, anterior view drawing. B. Right anterior gonopod, posterior view drawing. C. Left telopodite, posterior-mesal view drawing. D. Left telopodite, anterior-lateral view drawing. 
mesally with one mesad lobe $(f l)$, bluntly triangular in outline; distally with flattened, sickle-shaped lobe having mesal broad, rounded expansion forming canopy (Fig. 4 C). Posterior coxal fold ( $p c$ ) (Figs 4B, $5 \mathrm{~B})$ very low, less than half as high as $a c$, consisting of two low, parallel ridges separated by smooth trough; lateralmost ridge $(l r)$ with small, pointed triangular process $(t p)$ laterally; mesal ridge $(m r)$ continuing as sagittal ridge ending in small flap-like lobe $(f l)$. Telopodite (Figs 4D-E, 5C-D) leaving coxite over posterior coxal fold; femoral spine duplicated $(f e l, f e 2), f e 1$ very long, broader than $f e 2$, straight, concave at $1 / 3$ of mesal margin, terminally slightly curved, ending in sharp point; $f e 2$ slender, very long, as long as $f e l$; tibial spine $(t i)$ short, slender. Apical part of telopodite a broadly expanded sheet, with additional spine ( $a s)$ at base, with row of setalike spines $(s p)$ laterally, with several transverse ridges $(t r)$ across along outer rim surface.

\section{Females}

Adult females (paratypes) with 59-60 podous rings, no apodous rings. Length $16-18 \mathrm{~cm}$, width $13.4-$ $13.9 \mathrm{~mm}$.

Other non-gonopodal characters as in male, except:

- antennae not reaching past collum

- mandible without stipital lobe

- gnathochilarium without poorly sclerotized area on stipes

- collum with more rounded corners

LeGs. Shorter, tarsi and part of tibiae visible from above when legs extended laterad. Length of podomeres: femur $>$ tarsus $>$ tibia $>$ prefemur $\approx$ postfemur $>$ coxa $>$ claw. Setation of a posterior leg from midbody ring: coxa with 7 ventral setae; prefemur with 7 dorsal spinelike setae, 1 apocidorsal and several ventral fine setae; femur with 5 ventral fine setae; postfemur with 1 apicodorsal and 4 ventral fine setae; tibia with 1 apicodorsal and 5 ventral fine setae; tarsus with 1 dorsal and 4 ventral spinelike setae.

\section{Distribution}

Gia Lai and Kon Tum provinces, Vietnam (Fig. 8).

\section{Ecology}

Alienostreptus bicoloripes sp. nov. is found in a mixed tropical forest, formed mainly by broadleaf trees with tree ferns (Cyathea Sm. sp. and others) (Fig. 6A-D). At Kon Chu Rang Nature Reserve, adults were active in the daytime as well as at night. Juveniles were hiding all the time. Adults were distributed over a wide range of habitats, from the very bottom of valleys to the dry ridges with coniferous forest, which is not very typical of millipedes. The second visit to the Kon Chu Rang Nature Reserve was almost one and a half months earlier than the first one (26 March-6 April 2018), in early spring, and it was obviously the peak of this species' abundance. Numerous juveniles were observed along the streams in valleys (Fig. 2D). They mainly occupy a very specific habitat avoided by all other millipedes, viz, soaking wet clumps of leaf litter at the edge of streams and rivers, and also a surrounding area with a gradually decreasing water content. Leaf litter clumps caught by stones in streams also appeared as a habitat for juveniles. Sometimes they occupy troughs formed by rotten fallen trees next to the stream, which also contain a thick layer of wet leaf litter. Juveniles form loose aggregations in certain patches. They spend a few days in one spot, eating leaf litter and accumulating excrement in a 'chamber', then leave the 'chamber' and move to another spot. Juveniles may be resistant to acute flooding as the leaves 
they inhabit are already soaking wet, and after frequent rains, the water level rises and covers most of the habitat. Three juveniles of later stages were found roaming around on leaf litter near the stream.

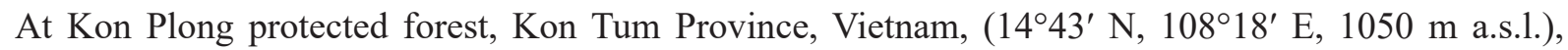
we have not collected specimens due to technical issues. Adult specimens of $A$. bicoloripes sp. nov. were found exclusively on the surface of leaf litter on hill slopes above streams. Some were eating mushrooms, others roaming.
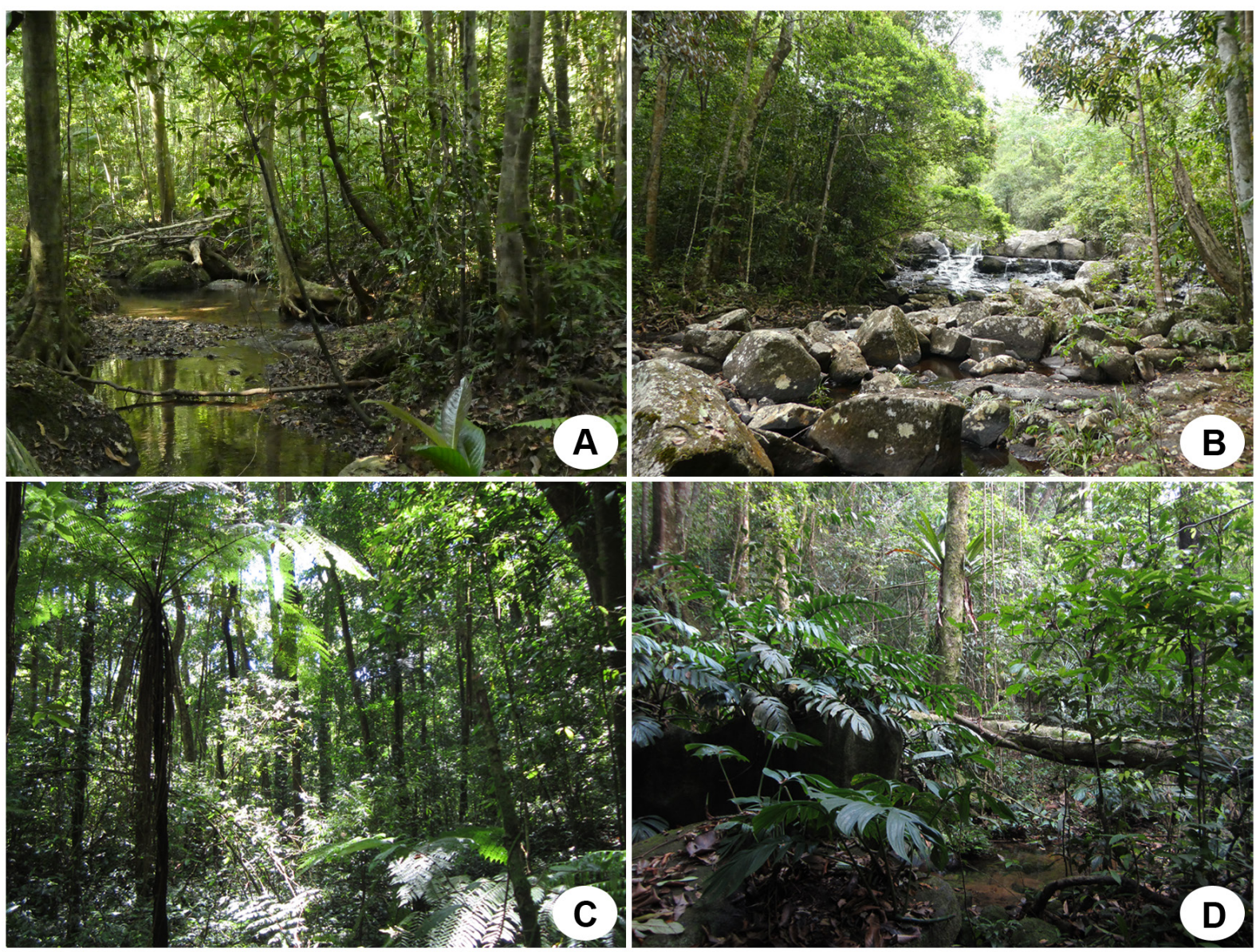

Fig. 6. Habitats of Alienostreptus bicoloripes sp. nov. in Vietnam. A-C. Kon Chu Rang Nature Reserve, Gia Lai Province. D. Kon Plong protected forest, Kon Tum Province.

\section{A 'copycat' specimen from Borneo?}

Clement Sim, Peter Petersen and Nicky Bay have taken photographs of a giant millipede from Kuching

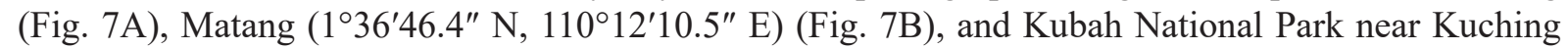
(Fig. 7C-D), Borneo (Malaysia: Sarawak) which has a very similar colour to that of A. bicoloripes sp. nov. According to the photos, there are, however, differences (Table 1).

Specimens from Borneo are not available. However, despite the unusual colour pattern shared with A. bicoloripes sp. nov., it is clear that it belongs to a different genus, based on the presence of ventral soft pads on the postfemora of the male legs. 
Table 1. Morphological differences between A. bicoloripes sp. nov. and Borneo specimens.

\begin{tabular}{lll}
\hline & Borneo specimens & A. bicoloripes sp. nov. from Vietnam \\
\hline Body colour & brown to dark brown & dark brown (almost black) \\
Antennae & pink & bi-coloured (as legs) \\
Legs & from coxae to postfemora pink, & from coxae to postfemora brownish orange, \\
tibiae and tarsi pale yellow \\
$\begin{array}{l}\text { Ventral soft } \\
\text { pads }\end{array}$ & present on both postfemora and tibiae & present only on tibiae \\
\hline
\end{tabular}

\section{Discussion}

The millipede subfamily Rhynchoproctinae currently comprises 36 species in 14 genera. As mentioned in Pimvichai et al. (2010), members of the subfamily form a monophyletic group by sharing three synapomorphic characters. However, the genus Alienostreptus differs from all other genera in the subfamily by having the femoral spine duplicated.

The photographed Bornean specimens (Fig. 7) show a similar colour pattern to that of the type specimens of Alienostreptus bicoloripes sp. nov., but there are differences in some details (see above). In the pet trade, there is a millipede looking similar to the Bornean specimens, it is sometimes referred to as
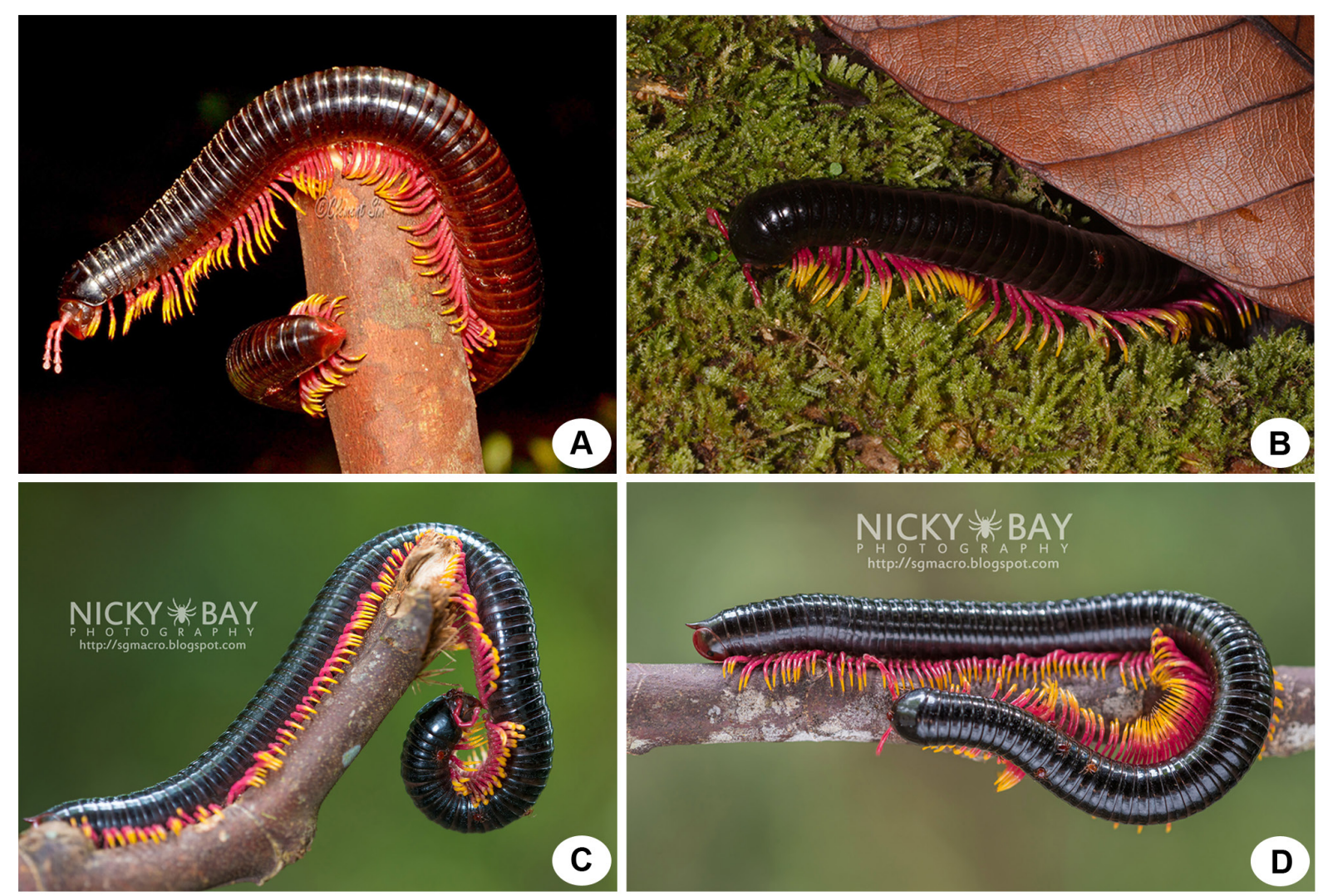

Fig. 7. Specimens from Borneo (Malaysia: Sarawak). A. Living female from Kuching (Photo by Clement Sim). B. Living male from Matang (Photo by Peter Petersen). C-D. Living male from Kubah National Park (Photos by Nicky Bay). 
Trigoniulus macropygus (Silvestri, 1897) - a blatant misidentification - or Flameleg millipede, originally also from Borneo and published on the internet, https:/www.youtube.com/watch? $\mathrm{v}=\mathrm{Vw} 3 \mathrm{IT} 5 \mathrm{~d} 4 \mathrm{PiI}$ and https://www.pinterest.dk/pin/411164640984124717/?autologin=true. We have reviewed original and subsequent descriptions of all 29 harpagophorid species listed from Borneo by Jeekel (2006). Many of the descriptions include notes on leg colour, but only for two species the description more or less reminds of A. bicoloripes sp. nov. These are two species of the endemic Bornean genus Lamellostreptus Demange, 1961:

Lamellostreptus complexus (Chamberlin, 1921), described from "Sarawak, Poak, near Kuching": "Legs and antennae pale ferrugineous, with the first two articles darker, brownish" (Chamberlin 1921: 63).

Lamellostreptus seriatus Demange, 1961, described from "Borneo": "Antennes et pattes jaune-rouge tranchant sur la coloration foncée du corps" (antennae and legs yellow-red, contrasting with the dark body colour) (Demange 1961: 66).

With the reservation that the descriptions of these (and other Bornean) species were based on preserved specimens, this suggests that the Bornean 'copycat' of Alienostreptus bicoloripes sp. nov. may be a species of Lamellostreptus, subfamily Harpagophorinae. In order to establish the identity of the Bornean species with certainty, a study of a male specimen is, however, needed.

Many tropical millipedes have pronounced seasonal differences in activity, often the males come out first, and then females arrive into the community. Males also disappear first, so at the end of the species' season, there are mainly females in the community.

Different areas have different climatic features, so the millipede communities at Kon Plong and Kon Chu Rang have a different timing of seasonal abundance, but for Kon Chu Rang we can assume that early spring is the peak season of $A$. bicoloripes sp. nov., with a fast decline in abundance over a few months until the absolute absence of adults.

The body colour changes with the age of the millipede. If juveniles are pale beige with yellowish legs, more mature stages acquire a darker brown colour with pronounced yellow legs and antennae, and then adults get the final coaly black body with bright yellow legs and antennae fading into red basally. At one point, there were at least three distinct age stages present in the community: juvenile medium size, juvenile later stage and adults. Juveniles of very first stages were not found. Based on this, we can assume that the life cycle of this species takes at least three years: two years of development and then one as an adult.

The striking colour pattern invites considerations about function. One possibility is that the colours are aposematic. However, living individuals of A. bicoloripes sp. nov. are not very willing to secrete their defensive fluids - only when placed in alcohol, they start excreting. The 'warning' may therefore refer to the particularly strong cuticle of $A$. bicoloripes sp. nov., rather than the chemical defence. At Cat Tien National Park in South Vietnam, many remnants of another harpagophorid, Thyropygus carli Attems, 1938, were found in mammalian excrements, but remnants of $A$. bicoloripes sp. nov. were never found in this substrate. Finally, a mimetic function cannot be excluded; although an obvious mimetic model has not been observed in Vietnam, the long colourful legs might suggest a scolopendrid centipede. In any case, the similarity of the colour patterns of $A$. bicoloripes sp. nov. and the so far unidentified, but most probably not congeneric Bornean species, is remarkable. 


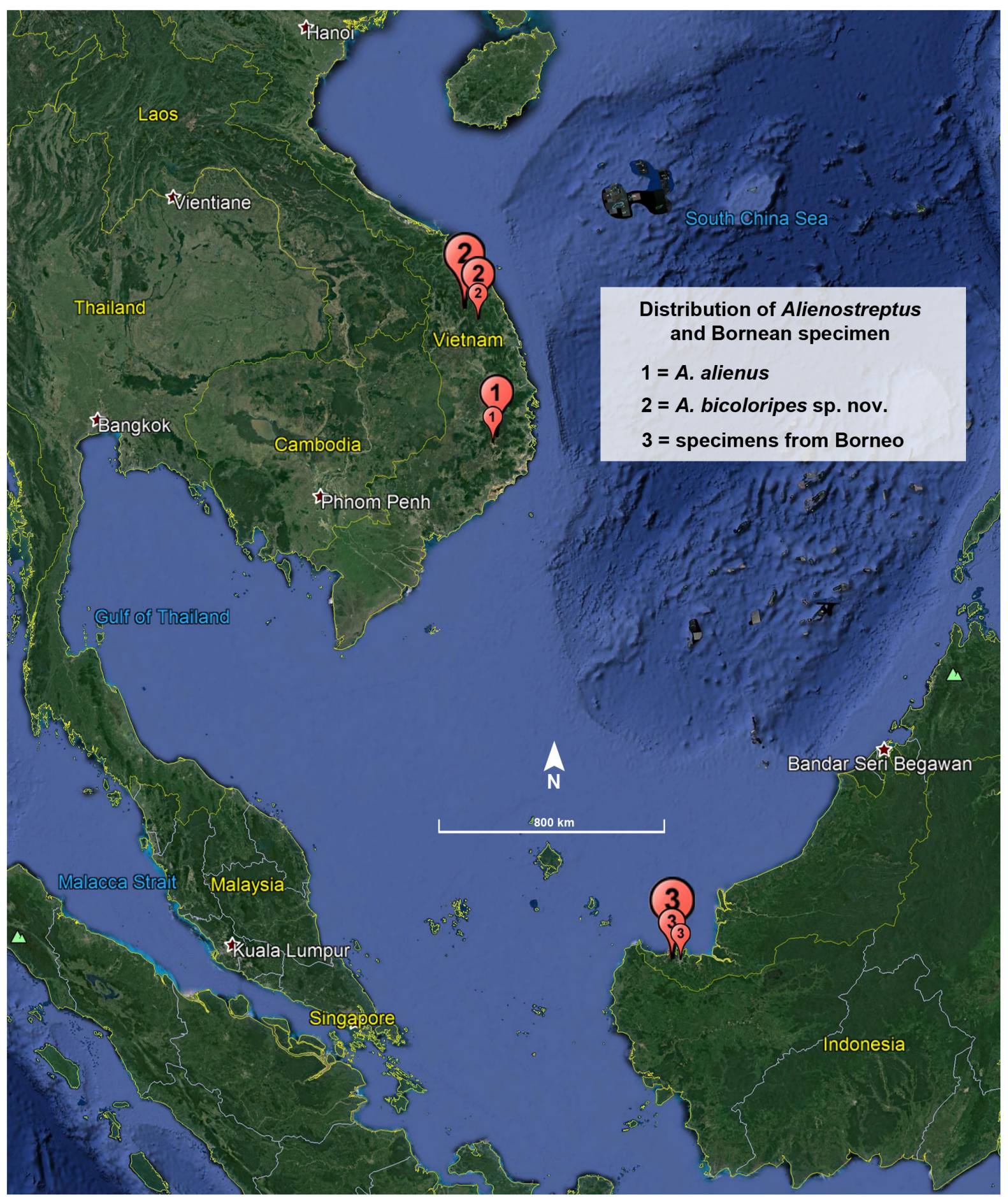

Fig. 8. Known distribution of Alienostreptus Pimvichai et al. 2010 spp. and superficially similar specimens from Borneo. Droplets vary in size only to improve readability. 


\section{Acknowledgements}

We thank Nicky Bay, Clement Sim and Peter Petersen for the photos of the Bornean specimens. This paper is partly a result of JC project "A step further in the Entomodiversity of Vietnam" supported through a grant issued by the capacity building Program of the Belgian Global Taxonomy Initiative National Focal Point that runs under the CEBioS program with financial support from the Belgian Directorate-General for Development Cooperation.

\section{References}

Attems C. 1936. Diplopoda of India. Memoirs of the Indian Museum 11: 133-323.

Attems C. 1938. Die von Dr. C. Dawydoff in Französisch Indochina gesammelten Myriopoden. Mémoires du Muséum national d'histoire naturelle, N.S. 6 (2): 187-321.

Attems C. 1942. Zur Kenntnis der indischen Harpagophoridae. Annalen des Naturhistorischen Museum Wien 52: 66-105.

Chamberlin R.V. 1921. New Chilopoda and Diplopoda from the East Indian region. Annals and Magazine of Natural History ser. 97 (5): 50-87. https://doi.org/10.1080/00222932108632489

Demange J.-M. 1961. Matériaux pour servir a une révision des Harpagophoridae. Mémoires du Muséum national d'histoire naturelle, Sér. A (Zool.) 24: 1-274.

Hoffman R.L. 1975. Studies on spirostreptoid millipeds. XI. A review of some Indonesian genera of the family Harpagophoridae. Journal of Natural History 9: 121-152.

https://doi.org/10.1080/00222937500770101

Jeekel C.A.W. 2006. A bibliographic catalogue of the Oriental Harpagophoridae (Diplopoda, Spirostreptida). Myriapod Memoranda 9: 5-58.

Pimvichai P., Enghoff H. \& Panha S. 2009. A revision of the Thyropygus allevatus group. Part 1: the T. opinatus subgroup (Diplopoda: Spirostreptida: Harpagophoridae). Zootaxa 2016: 17-50. https://doi.org/10.11646/zootaxa.2016.1.2

Pimvichai P., Enghoff H. \& Panha S. 2010. The Rhynchoproctinae, a southeast Asiatic subfamily of giant millipedes: cladistic analysis, classification, four new genera and a deviating new species from NW Thailand (Diplopoda: Spirostreptida: Harpagophoridae). Invertebrate Systematics 24: 51-80. https://doi.org/10.1071/IS09052

Zhang C.Z., Wang D.Q. \& Zhang F.X. 1997. Two new genera and four new species of Diplopoda from Wuling Mountains area. In: Song D. (ed.) Invertebrates of Wuling Mountains Area, Southwestern China: 508-522. Science Press, Beijing.

Manuscript received: 24 June 2020

Manuscript accepted: 6 August 2020

Published on: 20 October 2020

Topic editor: Rudy Jocqué

Desk editor: Radka Rosenbaumová

Printed versions of all papers are also deposited in the libraries of the institutes that are members of the EJT consortium: Muséum national d'histoire naturelle, Paris, France; Meise Botanic Garden, Belgium; Royal Museum for Central Africa, Tervuren, Belgium; Royal Belgian Institute of Natural Sciences, Brussels, Belgium; Natural History Museum of Denmark, Copenhagen, Denmark; Naturalis Biodiversity Center, Leiden, the Netherlands; Museo Nacional de Ciencias Naturales-CSIC, Madrid, Spain; Real Jardín Botánico de Madrid CSIC, Spain; Zoological Research Museum Alexander Koenig, Bonn, Germany; National Museum, Prague, Czech Republic. 